\title{
Ankara'da Özel Bir Eğitim ve Rehabilitasyon Merkezinde Tedavi Gören Serebral Palsi Tanılı Çocuk Sahibi Olan Ailelerde Sağlık Okuryazarlığının İncelenmesi
}

Investıgation of Health Literacy in Families with Children with Cerebral Palsy Treated in a Special Education and Rehabilitation Center in Ankara

Mehmet Fatih HALATCI ${ }^{1}$, Hacer DEMIRKÖSE ${ }^{2}$, Mustafa Necmi ÍLHAN ${ }^{3}$

${ }^{1}$ Gazi Üniversitesi, Tıp Fakültesi, Halk Sağlığı Ana Bilim Dalı, Ankara, Türkiye

${ }^{2}$ Arş. Gör. Gazi Üniversitesi Tıp Fakültesi, Halk Sağlığı Ana Bilim Dalı, Ankara, Türkiye

${ }^{3}$ Prof. Dr. Gazi Üniversitesi, Tıp Fakültesi, Halk Sağlığı Ana Bilim Dalı, Ankara, Türkiye

\section{Öz}

\begin{abstract}
Amaç: Çalışma, Ankara'da özel bir eğitim ve rehabilitasyon merkezinde tedavi gören serebral palsi (SP) tanılı çocuğa sahip olan ailelerde sağlık okuryazarlığının (SOY) incelenmesi için amaçlanmıştır. Gereç ve Yöntem: Çalışmaya Yeni Kurtuluş Özel Eğitim ve Rehabilitasyon Merkezinde tedavi gören, SP'li çocuğa sahip 200 ebeveyn dâhil edildi. Bu bireylere, Türkiye Sağıı Okuryazarlığı Ölçeği-32 ve 49 soruluk anket uygulandı. Araştırma, SPSS 15,0 programıyla analiz edildi. Sonuçlar: SP'li çocuğa sahip ailelerde yetersiz - sınırlı SOY düzeyi \%64 olarak bulundu. SP'li çocuklara bakım verenlerin anneler olması SOY'da anneleri ön plana çıkarmıştır. Tartışma: SOY düzeylerinin artııılması ebeveynlerin bakım verme bilincini, çocuğun sağlık düzeyini artıracağı için önemlidir.
\end{abstract}

Anahtar Kelimeler: Serebral Palsi; Sağlık Okuryazarlığı; Aile; Bakımveren

\section{ABSTRACT}

Purpose: The study, it was aimed to examine health literacy $(\mathrm{HL})$ in families with children diagnosed with cerebral palsy (CP) treated at a special education and rehabilitation center in Ankara. Material and Methods: The study included 200 parents who were treated at the Yeni Kurtuluş Special Education and Rehabilitation Center and had children diagnosed with CP. Individuals, 49-question survey and Turkey Health Literacy Scale-32 was applied. The research was analyzed with SPSS 15,0 program. Results: Insufficient - limited SOY level was found to be $64 \%$ in families with children with CP. Mothers who care for children with $\mathrm{CP}$ are therefore HL brought mothers to the fore. Discussion: Increasing HL levels is important as it will increase parents' awareness of care and the child's health level.

Keywords: Cerebral Palsy; Health Literacy; Family; Caregiver 
Serebral Palsi (SP), gelişmekte olan fetal veya bebek beyninde meydana gelen ilerleyici olmayan, etkilenim sonucu oluşan, aktivite kısıtılığına neden olan, hareket gelişimindeki ve postürdeki kalıcı bozukluktur (Rosenbaum, Paneth, Leviton ve ark, 2007). SP'ye spastisite, tremor, kuvvetsizlik, atetoz, koordinasyon bozukluğu, rijidite gibi motor bozukluklar, bununla birlikte görme, konuşma, mental gerilik, işitme, davranış bozuklukları, epilepsi, konvülziyonlar ve algılama gibi problemler eşlik edebilir (Sade ve Otman, 1997). SP'ye eşlik eden bu durumlar, çocuğun özür durumunu artırmakta ve bununla birlikte gündelik yaşam faaliyetlerinde ve sosyal katılımında da kısıtılıklara neden olmaktadır (Mutlu, Akmeşe ve Günel, 2010). Aynı zamanda SP'li çocuğun problemleri bakım veren ebeveynlerini de etkilemektedir (Livanelioğlu ve Günel, 2009). Bundan dolayı meydana gelen problemlerin bilinmesi, erken tanınması ve uygun yaklaşımlarda bulunulması çocuk ve ebeveynleri için önem arz etmektedir (Pruitt ve Tsai, 2009). Çocuğun tedavisinin planlaması, gereksinimlerinin yerine getirilmesi ve rehabilitasyonda bakım verici rolü oldukça fazladır (Barry, Butler ve Gardner, 2001). SP'li çocuklar günlük yaşam faaliyetlerinde ve sosyal etkileşimlerinde yardıma intiyaç duyarlar. Bu yardımlar sağlık bakımı, tedavi, izleme vb. gibi hizmetleri kapsamaktadır (Zarit, 2004).

Bu olumsuz durumların üstesinden gelebilmek için ve SP'li bireye sahip ailelerin çocuklarının sağlığının olumlu yönde etkilenmesi için bakım veren aile bireyinin sağlık SOY düzeyinin bilinmesi ve mevcut durumlarının daha iyi düzeylere çıkarılması gerekmektedir. Sağıı̆ın düzgün bir şekilde sürdürülebilmesi için okuryazarlık becerileri gerekmektedir. Okuma becerileri de bireyin sağlık bilgilerine erişebilmesi, sağlık hizmetlerini kullanabilmesi ve kendi sağlığını yönetmesi açısından önemlidir (Morris, MacLean, Chew ve ark, 2006). SOY bireylerin okuryazarlık becerileri ile sağııları arasında bir köprü görevi görmektedir (Jovic-Vranes ve Bjegovic-Mikanovic, 2012).

Dünya Sağlık Örgütü, SOY'u "Bireylerin iyi sağlık halinin sürdürülmesi ve geliştirilmesi amacıyla sağlıkla ilgili bilgiye ulaşması, anlaması ve kullanması için gerekli olan bilişsel ve sosyal beceri kapasitesi" şeklinde tanımlamıştır (Kickbusch, Pelikan, Apfel ve ark, 2013). SOY bireyin kendi sağlığını tanımlaması, hastalığı hakkında bilgi sahibi olması, sağlığıyla alakalı geçerli kararlar vermesi, sağlık sisteminden hangi durumlarda ve zamanlarda yararlanmasını bilmesidir (Berberoğlu, Öztürk, İnci ve ark, 2018). Sağlık hizmetinin kaliteli olması için hastaların, sağlık durumu ile ilgili şikayetlerini doğru ifade etmeleri önemlidir. Hastaların hastalık ve tedavi hakkında anlamlı sorular sormaları, iletilen tıbbi bilgi ve tedavi talimatlarını anlayabilmeleri beklenmektedir. Düşük SOY seviyesinin sağlık ile ilgili bilgileri anlayabilmede zayıflı̆g, söylenenleri yerine getirmede zorluklara ve sağlık hizmetlerine erişmede sorunlara yol açmaktadır (Tanrı̈ver, Yıldırım, Ready ve ark, 2014).

Hastalıkların temel nedenlerine yönelerek sadece tedavi üzerine odaklanmamış ve kişilerin sağlığını ve yaşam kalitesini korumak ve yarar sağlamak için sosyal ve çevresel müdahaleleri kapsamıştır. Sağlığın geliştirilmesi eylemi ve karar almanın merkezinde insanın yer alması süreçlerin etkili olmasında önemlidir. Eğitim ve bilgiye erişim, kişinin ve toplumun etkili katılımını ve sorumluluk almaları için gereklidir (World Health Organization 2016).

Türkiye de yapılmış bir SOY Araştırması sonucunda \%64,6 yetersiz-sorunlu SOY düzeyi saptanmıştır. Bu bulgu ile 53 milyon Türkiye erişkin nüfusu düşünüldüğünde, 35 milyon kişinin yetersizsorunlu SOY'a sahip olduğuna işaret etmektedir (Tanrıöver, Yıldırım, Ready ve ark, 2014). SOY'un doğru sağılk sonuçlarını ortaya çıkarmada önemli bir faktör olduğunu ve uygun eylem gelişimi için geliştirilmesinin gerekliliği vurgulanmıştır (Panizzon, 2011).

Literatürde çalışmaya başlamadan önce yaptığımız taramada SP tanılı çocuk sahibi olan ailelerin SOY'unu inceleyen bir çalışmaya rastlanmamıştır. Bu çalışmada Ankara'da özel bir eğitim ve rehabilitasyon merkezinde tedavi gören SP tanılı çocuk sahibi olan ailelerde SOY durumu incelenmiştir.

\section{GEREÇ VE YÖNTEM}

Çalışmamıza Kasım 2019- Ocak 2020 tarihleri arasında Yeni Kurtuluş Özel Eğitim ve Rehabilitasyon Merkezinde tedavi gören ve SP tanısı konmuş hastaların aile bireyleri dâhil edildi. Çalışmamızda evrenin tamamına ulaşılmış olup, 200 kişi ile gerçekleştirilmiştir. Bireylere çalışma hakkında bilgi verildi ve araştırmaya katılan bireylerden bilgilendirilmiş onam formu alındı. Çalışmaya katılan bireylere 49 soruluk anket ve Türkiye Sağlık Okuryazarlık Ölçeği-32 (TSOY-32) uygulandı. Yapılacak bilgilendirme, anket ve uygulanan ölçek birebir ve yüz yüze yapıldı. Bir anketin uygulama süresi ortalama 15-20 dakikadır. Araştırma kesitsel tipte bir araştırmadır. Araştırma verisi SPSS 15,0 istatistik paket programı aracılığıyla 
değerlendirilmiştir. Tanımlayıcı istatistikler ortalama ( \pm ) standart sapma, ortanca (min; maks), frekans dağılımı ve yüzde olarak sunulmuştur. İstatistiksel yöntem olarak Ki Kare kullanılmıştır. İstatistiksel anlamlılık değeri $p<0.05$ olarak kabul edilmiştir.

SOY ölçümünde referans alınacak kavramsal çerçevenin SOY'un tanımı gereği toplumsal özellikler ve sağlık hizmet sunumunun yapısıyla uyumlu olması önemlidir. Bu nedenle TSOY-32 ölçeği geliştirilirken, Avrupa SOY araştırması için geliştirilen kavramsal çerçeve referans alınmış; Türkiye'nin toplumsal özellikleri, toplumun sağlık düzeyi ve sağlık sisteminin yapısına uyarlılığı dikkate alınarak oluşturulmuştur. Böylelikle "tedavi ve hizmet" ile "hastalıklardan korunma/sağlığın geliştirilmesi" olmak üzere iki boyut; "sağlıkla ilgili bilgiye ulaşma", "sağlıkla ilgili bilgiyi anlama", "sağlıkla ilgili bilgiyi değerlendirme" ve "sağlıkla ilgili bilgiyi kullanma/uygulama" olmak üzere dört süreçten oluşan bir matris geliştirilen ölçeğin temelini oluşturmuştur. Ölçek matristeki sekiz farklı gözle ilişkilendirilmiş, her bir göze karşılık dört soru olmak üzere toplam 32 sorudan oluşmaktadır. Ölçeğin değerlendirilmesinde; indeksler HLS-EU (Avrupa SOY Çalışması) çalışmasında olduğu şekilde 0 ile 50 arasında olacak şekilde standardize edilmiştir. Hesaplama sonrasında, 0 en düşük SOY'u ve 50 en yüksek SOY'u göstermektedir. Aşağıdaki puanlamaya göre SOY;

(0-25) puan: Yetersiz sağlık okuryazarlığı

(>25-33) : Sorunlu - sınırlı sağlık okuryazarlığı

(>33-42) : Yeterli sağlık okuryazarlığı

(>42-50) : Mükemmel sağlık okuryazarlığı, olarak tanımlanmaktadır (Okyay ve Abacıgil, 2016).

Ki kare tabloları oluşturulurken yetersiz ve sorunlu-sınırlı SOY grubu birleştirilerek "yetersizsınırlı sağlık okuryazarlığı", "yeterli" ve "mükemmel sağlık okuryazarlığı" grubu birleştirilerek "yeterli-mükemmel sağlık okuryazarlığı”, annenin ve babanın eğitim durumu kriterlerinde ortaokul ve lise birleştirilerek "ortaokul-lise", medeni durumda bekar ve eşinden ayrı birleştirilerek "bekar ", anketi yapanın algılanan sağlığında iyi ve mükemmel birleştirilerek "mükemmel-iyi " şeklinde gruplandırımıştır. Anne yaşı çeyrek persentillere denk gelen değerlere göre dört kategoriye ayrılıp gruplandırılmıştır.

\section{SONUÇLAR}

Araştırmaya dahil edilen bireylerin yetersiz-sınırlı SOY düzeyi $\% 64,0$, yeterli-mükemmel SOY düzeyi $\% 36,0$ olarak bulunmuştur.

Araştırmaya katılanların \%78'inin kadındır. SP'li bireylerde bakım verenler genellikle anneler olduğu için çalışmamıza katılan kadın sayısı fazladır.

Annelerin yaş ortalamasını $36,35 \pm 8,24$, yaş ortancası $36,0(18,0-62,0)$, babaların yaş ortalaması $39,43 \pm 8,41$, yaş ortancası 39,0(25,0-62,0)'dır. Annenin yaşına göre SOY açısından araştırmaya dahil edilen 29 yaş ve altı annelerin \%22,0'si, 30-36 yaş annelerin $\% 37,7$ 'si, 37-42 yaş annelerin \%49,0'ı, 43 ve üstü yaş annelerin \%34,8'i yeterli-mükemmel SOY düzeyine sahiptir.

Araştırmamıza katılan annelerin $\% 53,5$ 'i, babaların \%52,0'ı ortaokul-lise eğitim düzeyine sahiptir. Eğitim durumu ilkokul ve altı olan annelerin \%23,0'ü, ortaokullise mezunu olanların \%36,4' ü, yükseköğretim mezunu olanların ise $\% 59,4$ 'ü yeterli-mükemmel SOY'a sahiptir.

Medeni duruma göre evli olanların \%33,3'ü, bekar olanların \%64,7'si yeterli-mükemmel SOY'a sahiptir. Annelerin \%15,0'inin çalıştığı görülmüştür. Anne çalışma durumuna göre çalışan annelerin \%60,3'ü, çalışmayan annelerin \%31,8'i yeterli-mükemmel SOY düzeyindedir.

Aylık gelir durumunu çok iyi olarak beyan edenler $\% 10,5$ olarak görülmüştür. Geliri giderinin altında olanların \%27,4'ü, geliri giderine eşit olanların \%35,0'ı, geliri giderinin üstünde olanların \%66,7'si yeterlimükemmel SOY'a sahiptir.

Ailelerin \%69,0'ının evini çocuklarının SP hastalığına ve yürüme engeline göre dizayn etmediği gözlenmiştir. Evini dizayn etmeyenlerin \%28,3'ü, evi dizayn edenlerin \%53,2'si yeterli-mükemmel SOY'a sahiptir. Bu fark istatistiksel olarak anlamlıdır $(p=$ 0,001).

Ebeveynlerin psikolojik yardım alma durumlarına göre SOY durumları değerlendirildiğinde, yardım almayanların almayanların \%31,5'i, alanların \%55,3'ü yeterli-mükemmel SOY düzeyine sahiptir $(p=0,010)$.

Ailelerin \%82,5'inin evde çocuklarına fiziksel egzersiz programı uyguladığı belirlenmiştir. Çocuklarına evde egzersiz uygulamayanların \%14,3'ünün, evde egzersiz uygulayanların ise \%40,6'sının yeterli-mükemmel SOY'a sahip olduğu dikkat çekmiştir $(p=0,006)$.

Ebeveynlerin algılanan sağlık durumuna göre SOY düzeyleri karşılaştırıldığında, kendi sağlığını mükemmel-iyi hissedenlerin \%10,3'ü, orta hissedenlerin \%31,4'ü, kötü-çok kötü hissedenlerin $\% 54,5$ 'i yeterli-mükemmel SOY'a sahiptir. 
Tablo 1. Ebeveynlerin sağlık okuryazarlığı düzeylerinin dağılımı, Ankara, 2020

\begin{tabular}{lll}
\hline & Sayı & $(\%)^{*}$ \\
\hline Sağlık Okuryazarlığı Düzeyi & & \\
\hline Yetersiz-Sınırı Sağlık Okuryazarlığı $(\leq 33)$, & 128 & 64,0 \\
\hline Yeterli-Mükemmel Sağlık Okuryazarlığı (>33-50) & 72 & 36,0 \\
\hline Sütun Yüzdesi & &
\end{tabular}

\section{TARTIŞMA}

Durusu ve arkadaşlarının yapmış olduğu Türkiye SOY Araştırmasında katılanların \% 64,6'sının yetersiz-sorunlu SOY düzeyine sahip oldukları bulunmuştur (Tanrı̈ver, Yıldırım, Ready ve ark, 2014). Çalışmamı literatürle benzerlik göstermektedir. SP’li çocuğu olan ailelerin hastalığın tanısının koyulmasıyla devamlı hastaneye olan bağlılık ve sağlık ile alakalı konularda sürekli bir uğraş içinde olduğunu görmekteyiz. Böyle bir yakın ilişkiye rağmen yetersiz-sorunlu SOY oranı oldukça yüksektir. Araştırmamız Ankara ilinde yapılmış olmasına rağmen SOY düzeyi en düşük olan Bulgaristan'ın gerisinde olması ciddi bir halk sağlığı problemi olmasının yanında SP'li çocuklar içinde ciddi bir sorunun varlığını ortaya çıkarmaktadır.

Avrupa SOY Araştırmasında yaşın ilerlemesinin SOY için risk faktörü olduğu belirtilmiştir (Sorensen, Pelikan, Röthlin ve ark, 2015). İlerleyen yaş ile birlikte yetersiz-sınırlı SOY'un bilişsel fonksiyonlarda ve duyusal yeteneklerde azalmanın neticesinde ortaya çıktığı bilinmektedir (Sorensen, Pelikan, Röthlin ve ark, 2015). Bizim çalışmamızda literatürden farklı olarak SOY'da genç yaştan orta yaşa doğru yükselme gözlenmektedir. Bu yükselmenin sebebi olarak engelli çocuğa sahip olmanın ve çocuğa bakım vermede ebeveynin kendini geliştirmek zorunluluğuna bağlı olarak SOY'da yükselme gözlendiği ancak daha önceki çalışmalarda da gözlendiği gibi yaşın ilerlemesinin getirdiği birtakım olumsuzluklarla SOY'un tekrar azalmaya başladığı düşünülmektedir.

Araştırmamızda annelerin eğitim düzeylerinin yaklaşık yarısının ortaokul-lise seviyesinde görülmüştür. Bunun nedeni olarak araştırmamızın Ankara şehir merkezinde yapılmasından kaynaklandığını düşünmekteyiz. Araştırmamızda eğitim düzeyi arttıkça SOY'un arttığı bulundu. Kutner ve arkadaşlarının yaptığı çalışmada benzer durum gözlenmiştir (Kutner, Greenburg, Jin ve ark, 2006). Eğitim durumunun artmasının SOY'un artmasında doğrudan etkisi olduğunu öngörmekteyiz.
Çalışmamızda annelerin dörtte üçünden fazlasının çalışmadığı görülmüştür. Çocuğa primer bakım vermekte olan ebeveynin çoğunlukla annelerin olması annelerin çalışma oranın düşük olmasında etkili olduğu düşünülmektedir (Hoekstra-Weebers, Jaspers, Kamps ve ark, 2001). Anne çalışma durumu arttıkça SOY'un da arttığı görülmüştür. Özkan ve arkadaşlarının yaptığı çalışmada da benzer sonuçlar elde edilmiştir (Özkan, Dikmen, Tuzun ve ark, 2016). Hane halkının geliri artıkça imkanların artması, ayrıca çalışılan ya da yapılan meslek kadının çalıştığı ortamda bulunduğu konumdan dolayı bilincinin artması ve kişiler ile iletişim halinde olması SOY'u artırmış olabilir.

Çalışmamızda ekonomik durumunu iyi olarak beyan edenlerin sayısı arttıkça SOY düzeyinin daha yüksek olduğu görülmüştür. Palumbo ve arkadaşlarının yapmış olduğu çalışmada gelir düzeyini iyi olarak beyan edenler artıkça SOY'un arttığı görülmüştür (Palumbo, Annarumma, Adinolfi, ve ark, 2016). Gelir düzeyi arttıkça daha iyi fırsatlara ve imkanlara sahip olunması, ulaşabileceği alanların daha geniş olması SOY'un yüksek olmasıyla orantılı olabilir.

Çalışmamızda evli olanların SOY düzeyinin bekar olanlara göre daha düşük SOY düzeyine sahip olduğu görülmüştür. Yapılmış bir çalışmada yetersiz SOY düzeyine sahip olanların \%91,3'ünün evli olanlardan oluştuğu bildirilmiştir (Jovic-Vranes, BjegovicMikanovic, Marinkovic, 2009). Bekar olan ebeveynlerin çocuklarının sorumluluğunu tek başlarına almak zorunda kaldıklarından kendilerini geliştirmek zorunda kaldıkları düşünülebilir.

Başta nöromusküler hastalığı olan çocuklar olmak üzere fiziksel engeli bulunan çocuklar için ev içinde gerçekleştirilebilecek bazı düzenlemeler çocuğun ebeveyne olan bağımlılığını azaltabilir (Aktaş, 2010). Evi çocuğun hastalığına göre dizayn etme durumuna bağlı SOY'a bakıldığında evi dizayn etmeyenlerin üçte ikisinden fazlasının SOY düzeyi yetersiz-sınırlı düzeydeydi. Literatürde de belirtildiği gibi ev dizaynı çocuğun durumu ve sağlığı açısından önemlidir (Çelik, 2014). Aileler maddi durumlarındaki birtakım imkansızlıkların engel olduğunu, ev dizaynı noktasında bilgilerinin yetersiz olduğunu ve bu dizaynlar hakkında bir uzman tarafından bilgilendirilmediklerini belirtmişlerdir. Ailelerin bu konuda bilgilendirilmesinin hem ailenin SOY düzeyinde artmaya hem de o evde 
yaşamını sürdüren çocuk için daha sağlıklı bir ortam sağlayacağını öngörüyoruz.

Ev egzersiz programları, sağlıkla ilgili hedeflenen sonuçlara ulaşmak için uygulanan ve engelli çocuğun ev ortamında bakım verenin yardımı ile gerçekleştirdiği terapötik programlardır (Novak, Cusick ve Lowe, 2007). Fiziksel engelli egzersiz uyguladığı görülmektedir. Ebeveynler fizyoterapistleri tarafından bilgilendirildiklerini belirtmişlerdir. Özdinçer'in çalışmasında ev programının etkinliğinin arttırılması hususunda aile eğitiminin önemli olduğu bildirilmiştir (Özdinçer, 2002). Çocuğun fiziksel gelişimi açısından sadece kurumlarda verilen eğitim yeterli olmayıp ailenin ev egzersizlerini düzenli olarak yaptırmaları gerekir. $\mathrm{Bu}$ durumda aile bireylerinin eğitim durumu ön plana çıkmakta ve eğitim ile ilgili SOY doğru orantıda bağlantılı olduğu için SOY'un yüksek olması evde egzersiz uygulanma durumunu pozitif yönde etkileyebilir.

Çalışmamıza bakıldığında ebeveynleri yarısından fazlasının psikolojik yardım almadığı görülmüştür. Psikolojik yardım alan ya da almakta olan ebeveynlerin almayanlara göre SOY düzeyinin daha düşük olduğu dikkat çekmiştir. Yüksel'in yapmış olduğu çalışmada, psikolojik destek alan annelerin kendilerini ifade etme, eş ve çocuklarını anlayabilme, etkili iletişim kurabilme ve problem çözme becerilerinde gelişme olduğunu belirtmişler ve bu durumun depresyon belirtilerini de azalttığını bildirmişlerdir (Yukay Yüksel, 2007). Literatüre bakıldığında ailelerin psikolojik olarak yardım alması gerekliliği vurgulanmış olup hem ebeveynlerin kendileri ile hem de çocuk ile olan ilişkilerinin daha sağlıklı olması açısından bu duruma intiyaç vardır.

Algılanan sağlığın mortalite ile ilişkili olduğu ayrıca morbidite, yeti yitimi ve sağlık hizmeti kullanımının belirleyen iyi bir ölçüt olduğu yapılan araştırmalarda saptanmıştır (Tüzün, Aycan ve İlhan, 2015). Algılan sağlığı mükemmel-iyi olanların SOY'u , kötü-çok kötü hissedenlere göre daha düşük bulunmuştur. Yapılan çalışmalarda bizim çalışmamızdan farklı olarak SOY ile algılanan sağlık arasında pozitif bir ilişki olduğu bildirilmiştir (Furuya, Kondo, Yamagata ve ark, 2015). Bu durum bize bu çalışmadaki ebeveynlerin SP'li çocuğa sahip olmasının ve bakım yükünün fazla olmasından kaynaklı algılanan sağlık ve SOY arasındaki ilişkinin daha değişken bir duruma geldiğini göstermektedir.

Görülme sıklığının artığını düşünecek çocukların rehabilitasyonuna yönelik merkezlerinin azlığı ve bu merkezlere bireylerin ulaşmasındaki zorluklar, aile desteğinin ve ev egzersiz programının önemini artırmaktadır (Mutlu, Tarsuslu, Günel ve ark, 2007). Çalışmamızda SOY düzeyi düşük olarak bulunsa da büyük bir çoğunluğun çocuğa evde

olursak SP ciddi bir halk sağlığı problemidir. SP'li bireyler daha çok önemsenmeli ve bu bireylere bakım verenler daha çok bilinçlendirilmelidir.

Halkın, SP'li çocuğa sahip ebeveynlerin ve bakım verenlerin SOY düzeylerinin artırılması bakım verme bilincini, çocuğun sağlık düzeyini artıracağından ve ikincil komplikasyonları iyileştireceğinden SOY'un artırılma çalışmaları önemsenmeli ve desteklenmelidir.

Alanında yapılan bizim bildiğimiz ilk çalışma olup farklı bölge ya da kurumlarda yapılması önem arz etmektedir.

\section{Kaynaklar}

Rosenbaum, P., Paneth, N., Leviton, A., Goldstein, M., Bax, M., Damiano, D., Jacobsson, B. (2007). A report: the definition and classification of cerebral palsy April 2006. Dev Med Child Neurol Suppl, 109(suppl 109), 8-14.

Sade, A. (1997). Otman S. Serebral paralizide kullanılan çeşitli tedavi yöntemleri. Sade A, Otman $S$ (Editörler). Serebral paralizide değerlendirme ve tedavi yöntemleri'nde. Ankara, 54-101.

Mutlu, A., Akmeşe, P. P., \& Günel, M. K. (2010). Değişik özür seviyesindeki serebral palsili çocukların annelerinin depresyon düzeyleri farklı mıdır? Yeni Tıp Dergisi, 27(2), 87-92

Livanelioğlu, A., \& Günel, M. (2009). Serebral palside fizyoterapi. Ankara: Yeni Özbek Matbaasl, 5-12.

Pruitt, D. W., \& Tsai, T. (2009). Common medical comorbidities associated with cerebral palsy. Physical Medicine and Rehabilitation Clinics, 20(3), 453-467.

Barry, M., Butler, C., and Gardner, J. (2001). Early diagnosis and interventiw York: Marcel Dekker Inc, 65-72.

Kasuya, R.T., Polgar-Bailey, M.P., and Robbyn Takeuchi, M. MPH. (2000). Caregiver burden and burnout a guide for primary care physicians. Postgraduate medicine, 108(7), 119.

Zarit, S.H. (2004). Family care and burden at the end of life. Canadian Medical Association Journal, 170(12), 1811-1812.

Morris, N. S., MacLean, C. D., Chew, L. D., and Littenberg, B. (2006). The Single Item Literacy Screener: evaluation of a brief instrument to identify limited reading ability. BioMed Central's family practice, 7(1), 21

Jovic-Vranes, A. and Bjegovic-Mikanovic, V. (2012). Which women patients have better health literacy in Serbia? Patient education and counseling, 89(1), 209-212.

Kickbusch, I., Pelikan, J. M., Apfel, F., and Tsouros, A. (2013). Health literacy. WHO Regional Office for Europe, 87-92.

Berberoğlu, U., Öztürk, O., İnci, M. B., and Ekerbiçer, H. Ç. (2018). Bir Aile Sağlığı Merkezine Kayıtlı 18-65 Yaş Grubu Bireylerdeki Sağlık Okuryazarlığı Durumunun Değerlendirilmesi. Sakarya Tıp Dergisi, 8(3), 575-581.

Tanrı̈ver, M. D., Yıldırım, H. H., Ready, F. N. D., Cakır, B., and Akalın, H. E. (2014). Sağlik okuryazarliği araştirmasi. Sağlık-Sen Yayınlart, 17-21.

Panizzon, M. (2011). Migration and trade: prospects for bilateralism in the face of skill-selective mobility laws. Melbourne Journal of International Law, 12, 95.

Okyay, P., \& Abacıgil, F. (2016). Türkiye sağlık okuryazarlığı ölçekleri güvenilirlik ve geçerlilik çalışması. Avrupa sağlık okuryazarlığ ölçeği Türkçe uyarlaması (ASOY-TR). Mayıs, 24-41.

Gülşen, B. and Özer, F.G. (2009). Engelli Çocuğa Sahip Ailelerin Stresle Bas Etme Durumları. TAF Preventive Medicine Bulletin, 8(5). 
Sorensen, K., Pelikan, J. M., Röthlin, F., Ganahl, K., Slonska, Z., Doyle, G., and Falcon, M. (2015). Health literacy in Europe: comparative results of the European health literacy survey. European Journal of Public Health, 25(6), 1053-1058.

Kutner, M., Greenburg, E., Jin, Y., and Paulsen, C. (2006). The Health Literacy of America's Adults: Results from the 2003 National Assessment of Adult Literacy. National Center for Education Statistics, 27-35.

Duong, V. T., Lin, I. F., Sorensen, K., Pelikan, J. M., Van den Broucke, S., Lin, Y. C., and Chang, P. W. (2015). Health literacy in Taiwan: a population-based study. Asia Pacific Journal of Public Health, 27(8), 871-880.

Jovic-Vranes, A., V. Bjegovic-Mikanovic, and Marinkovic, J. (2009). Functional health literacy among primary healthcare patients: data from the Belgrade pilot study. Journal of public Health, 31(4), 490-495.

Hoekstra-Weebers, J.E., Jaspers, J.P., Kamps, W.A., Klip, E.P., (2001). Psychological adaptation and social support of parents of pediatric cancer patients: a prospective longitudinal study. Journal of Pediatric Psychology, 26, 225-35.

Özkan, S., Dikmen, A. U., Tuzun, H., and Karakaya, K. (2016). Prevalence and determiners of health literacy in Turkey. European Journal of Public Health, 26, 1.

Palumbo, R., Annarumma, C., Adinolfi, P., Musella, M., and Piscopo, G. (2016). The Italian health literacy project: insights from the assessment of health literacy skills in Italy. Health Policy, 120(9), 1087-1094. 141.

Aktaş, E. (2010). Fiziksel engelli çocuk ve ailesinin evde bakım gereksinimine karşı 1 şı tutucu araştırmaların sistematik incelenmesi. Yüksek Lisans Tezi. İstanbul: Marmara Üniversitesi Sağllk Bilimleri Enstitüsü, 80-85.

Çelik, S. (2014). Zihinsel Engelli Bireylerde Kaza/Yaralanmaların Önlenmesinde Hemșirenin Rolü. Çağdaş Tıp Dergisi, 4(2), 100-97.

Novak, I., A. Cusick, and Lowe, K. (2007). A pilot study on the impact of occupational therapy home programming for young children with cerebral palsy. American Journal of Occupational Therapy, 61(4), 463-468.

Mutlu, A., Tarsuslu, T., Günel, M. K., \& Livanelioğlu, A. (2007). Serebral paralizili çocuklarda ev egzersiz programının etkinliğinin incelenmesi Orijinal Araştırma. Türk Pediatri Arşivi, 42(3), 112-116.

Özdinçer, S. (2002). Nöromüsküler hastalıklı çocukların evde bakım gereksinimleri, ailelerin evde bakımda yaşadığı güçlükler ve olanakları.Yüksek Lisans Tezi. Marmara Üniversitesi, 53-58.

Yukay Yüksel, M. (2007). Otistik çocuğa sahip ailelerle yapılan grupla psikolojik danışma çalıșmasının ailelerin depresyon ve problem çözme becerileri üzerine etkisi. Marmara Üniversitesi Atatürk Eğitim Fakültesi Ĕ̈itim Bilimleri Dergisi, 25,10-14.

Tüzün, H., Aycan, S. and İlhan, M.N. (2015). Impact of comorbidity and socioeconomic status on quality of life in patients with chronic diseases who attend primary health care centres. Central European Journal of Public Health, 23(3), 188-194.

Furuya, Y., Kondo, N., Yamagata, Z., and Hashimoto, H. (2015).Health literacy, socioeconomic status and self-rated health in Japan. Health promotion international, 30(3), 505513. 